\title{
Estimation of risk management effects on revenue and purchased feed costs on US dairy farms ${ }^{1}$
}

\author{
Joleen C. Hadrich ${ }^{* 2}$ and Kamina K. Johnson† \\ *Department of Agricultural and Resource Economics, Colorado State University, Fort Collins 80523-1172 \\ †USDA, Animal and Plant Health Inspection Service, Veterinary Services, Fort Collins, CO 80526
}

\begin{abstract}
Variations in milk and feed prices directly affect dairy farm risk management decisions. This research used data from the 2010 US Department of Agriculture-Agricultural Resource Management Surveys phase III dairy survey to examine how risk management tools affected revenues and expenses across US dairy farms. The survey was sent to 26 states and collected information on costs and returns to individual dairy farms. This research used the information from milk sales, crops sales, feed expenses, and farm and operator characteristics, as well as the use of risk management tools. Matching methodology was used to evaluate the effect of 5 independent risk management tools on revenues and expenses: selling milk to a cooperative, using a commodity contract to sell grain, feeding homegrown forage at a basic and intensive level, and use of a nutritionist. Results showed that dairy farms located in the Midwest and East benefit from selling milk to a cooperative and using commodity contracts to sell grain. Across the United States, using a nutritionist increased total feed costs, whereas a feeding program that included more than $65 \%$ homegrown forages decreased total feed costs. Results point to benefits from educational programming on risk management tools that are region specific rather than a broad generalization to all US dairy farmers.
\end{abstract}

Key words: dairy, risk management, matching methodology

\section{INTRODUCTION}

Feed cost management has been cited as one of the most important input cost control measures for dairy operations because it accounts for the largest share of total costs across herd sizes (USDA-ERS, 2007). Dairy

\footnotetext{
Received September 16, 2014.

Accepted May 4, 2015.

${ }^{1}$ The views expressed herein are those of the authors and do not necessarily reflect the views of the USDA.

${ }^{2}$ Corresponding author: joleen.hadrich@colostate.edu
}

farmers have been using various means of input quantity control measures to manage this large input cost, but even with these measures, purchased feed costs increased by $115 \%$ in California, by $56 \%$ in Wisconsin, and by $140 \%$ in New York from 2005 to 2010 (USDAERS, 2005, 2010). These states are typically the top 3 milk-producing states in the United States and represent small-scale (e.g., Wisconsin and New York) and large-scale (e.g., California) operations. In regions such as the Midwest (e.g., Wisconsin) and the East (e.g., New York), dairy farms typically have smaller herd sizes and raise their own feed for dairy cows, whereas in the West (California), herd sizes are larger than average, with feed typically purchased rather than grown on the farm (McDonald et al., 2007). The differing structure of dairy farms across the United States and the wide variation in purchased feed cost changes in these 3 states demonstrate the need for further analysis to determine how this variation may affect dairy input risk management decisions.

Dairy farmers commonly state they are most concerned with input, commodity, and milk price risk (Wilson et al., 1993; Harwood et al., 1999; Wolf and Olynk Widmar, 2014). Wilson et al. (1993) surveyed large-scale dairy farmers and found that older dairy producers preferred to be low-cost producers to manage risk, whereas younger dairy producers found forward contracting and debt management to be the 2 most important strategies. Additional price risk management tools included using insurance products to manage net farm income fluctuation, signing up for government program payments, or using commodity contracts as a hedging or speculating tool to stabilize profit, among other tools (Patrick and Musser, 1997; Harwood et al., 1999; Meuwissen et al., 2001; Khanal et al., 2010; Chang and Mishra, 2011; D'Antoni and Mishra, 2012; Kuethe and Morehart, 2012). Not all farms adopt risk management practices and some may choose to adopt multiple tools, whereas others may focus on one strategy. By using these different tools, dairy farms can help control input costs while stabilizing net farm income.

Previous studies evaluating risk management for dairy farms have shown that farm location and type 
affect farmers' perceptions of risk and risk management. To understand the difference between these risk management choices, it is important to compare similar farms with similar producer characteristics within a region. Most studies make this comparison at the herd-size level. A more robust analysis would make this comparison on multiple characteristics, such as herd size and farm location, as well as experience and education level of the principal operator. This analysis uses matching methodology, which allows us to evaluate the effect of risk management tools on farms with multiple similar characteristics (Imbens, 2004). Matching methodology has been applied to the dairy industry to demonstrate that using recombinant bovine somatotropin (rbST) resulted in increased production per dairy cow, decreased cost of production per hundredweight of milk produced, and increased labor and management income per operator on dairy farms in New York State (Tauer, 2009). Organic production was studied using matching methods and it was found that organic cow-calf operations experienced higher allocated costs compared with conventional operations (Gillespie and Nehring, 2012) and that organic crop producers did not realize increased incomes compared with conventional crop producers (Uematsu and Mishra, 2012). Mayen et al. (2012) found that organic technology was less productive than conventional farm technology when matching on-farm and operator characteristics using technical efficiency measures.

This study extends previous work by using matching methodology (Abadie et al., 2004; Imbens, 2004) to evaluate the effects of using 5 independent price risk management techniques on dairy farms across 8 states. The objective of this research was to identify the types of risk management strategies that are most effective in protecting the financial health of dairy producers across the United States. This provided us with an opportunity to compare risk management adoption data collected by the US Department of Agriculture-Agricultural Resource Management Surveys (USDA-ARMS) to understand how risk management varies at the state and herd levels. The results of this analysis also provided insights into what dairy producers are doing as opposed to what producers could do to manage risk.

\section{MATERIALS AND METHODS}

\section{Data Analysis Methods}

Matching methodology provides a method to estimate the effect of treatments and compare differences in performance across 2 similar groups. One group adopts the technology (treatment group); the other group does not (control group). The methodology is then used to estimate the direct average effect of a binary treatment on a scalar performance measure, which allows comparison of outcomes across pairs of matched treated and nontreated observations (Imbens, 2004).

Following Abadie et al. (2004) and Imbens (2004), let there be 2 potential outcomes:

$$
Y_{i}\left(W_{i j}\right)= \begin{cases}Y_{i}(0) & \text { if } W_{i j}=0 \\ Y_{i}(1) & \text { if } W_{i j}=1\end{cases}
$$

where $Y_{i}$ is the performance measure, $W_{i j}=1$ if risk management tool $j$ was used on farm $i$, and $W_{i j}=0$ if risk management tool $j$ was not used for farm $i=1, \ldots$, $N$. For each farm that uses risk management tool $j$, a matching farm is identified that does not use that tool. Because $Y_{i}(0)$ and $Y_{i}(1)$ are observable, the effect of the risk management tool on the performance measure is directly observable, such that $\left[Y_{i}(1)-Y_{i}(0)\right]$. The average treatment effect (ATT) for the subpopulation of the farms that adopted risk management tool $j$ can be represented as follows:

$$
A T T(\text { risk management })=\frac{1}{N_{1}} \sum_{i \mid W_{i j}=1}\left[Y_{i}(1)-Y_{i}(0)\right]
$$

where $N_{1}=\sum_{i} W_{i j}$ is the number of farms using risk management and $W_{i j}(1)$ indicates that the risk management tool was used. Specifically, ATT measures the effect of the group adopting the risk management tool using the tool on a performance outcome. The average treatment effect for the controls (ATC) - those farms not using risk management-is calculated as in equation [2] except that $N_{1}$ is replaced with $N_{0}$ to represent the number of farms that did not use risk management and $W_{i j}=0$ to indicate that the treatment was not received. Again, ATC measures the effect of the control group using the risk management tool on a performance outcome.

Matching estimators allowed us to find matched farms in the sample based on the set of specified characteristics. In nonmatching methodology papers, comparisons across groups are typically made comparing one characteristic, such as size of the operation; matching methodology allows us to match on multiple farm and operator characteristics, giving us more robust results. Because more than one variable was used for matching, we used a weighting matrix to match farms using risk management tools with those farms that do not use these tools. Following Abadie et al. (2004) and Imbens (2004), a weighting matrix was used to match farms in the opposite group that is the $m$ th closest (or nearest) 
to farm $i$ in terms of distance measured based on the norm of the distance metric. Let $\mathrm{k} \in M(i)$ denote the set of indices for the first $M$ matches for farm $i$ such that the potential outcomes can be represented as follows:

$$
\begin{gathered}
\hat{Y}_{i}(0)= \begin{cases}Y_{i}, & \text { if } W_{i j}=0 \\
\frac{1}{M} \sum_{k \in M(i)} Y_{k}, & \text { if } W_{i j}=1\end{cases} \\
\hat{Y}_{i}(1)= \begin{cases}Y_{i}, & \text { if } W_{i j}=1 \\
\frac{1}{M} \sum_{k \in M(i)} Y_{k}, & \text { if } W_{i j}=0\end{cases}
\end{gathered}
$$

The sample average treatment effect for the treated was estimated by:

$$
\hat{\tau}_{M}^{\text {sample }, t}=\frac{1}{N_{1}} \sum_{i: W_{i j}=1}\left[Y_{i}-\hat{Y}_{i}(0)\right] .
$$

The sample average treatment effect for the controls was estimated by:

$$
\hat{\tau}_{M}^{\text {sample }, c}=\frac{1}{N_{0}} \sum_{i: W_{i j}=0}\left[\hat{Y}_{i}(1)-Y_{i}\right]
$$

The distance metric chooses the optimal match using the diagonal matrix of the inverse of the covariate variances serving as weights such that,

$$
d_{A I}(x, z)=(x-z)^{\prime} \operatorname{diag}\left(\sum_{x}^{-1}\right)(x-z)
$$

where $\sum_{x}^{-1}$ is the covariance matrix of the covariates. Because this method is applied to the USDA-ARMS data, probability weights were included such that an observation represented a part of the population proportional to its weight using the pweight option with STATA (StataCorp, 2011). Additionally, the standard errors were updated to account for this weighting (Abadie et al., 2004).

\section{Survey Data}

Data from the 2010 USDA-ARMS phase III dairy were used to compare performance measures of dairy farms using risk management techniques versus dairy farms that do not use risk management techniques. The ARMS survey results provided comprehensive data on a nationally representative sample of dairy farms in the United States. Dairy producers from 26 states (Arizona, California, Colorado, Florida, Georgia, Idaho, Illinois, Indiana, Iowa, Kansas, Massachusetts, Kentucky, Michigan, Minnesota, Missouri, New Mexico, New York, Ohio, Oregon, Pennsylvania, Tennessee, Texas, Vermont, Virginia, Washington, and Wisconsin) completed the questionnaire that asked about farm and operator characteristics, costs, returns, production and marketing practices, and management decisions. Using the ARMS data allowed us to capture industry-wide variations, which are difficult to capture with singlesite survey data.

The top 8 dairy production states (California, Wisconsin, Idaho, Pennsylvania, Minnesota, Texas, Michigan, and New York) in 2010 were included in the analysis. Dairy states were included in the analysis if they provided over $4.25 \%$ of the national milk production in 2010. Data included 1,269 usable observations of conventional dairy producers who reported that the predominant source of revenue for their farms was the dairy enterprise. Organic dairy farms have production practices and feeding decisions that vary from those of conventional dairy farms (McBride and Greene, 2009). Due to these differences, this analysis was completed only on data for conventional dairy farms. The respective ARMS dairy population weights were applied, and the weighted sample of conventional dairy farms in the United States across the 8 states is presented in Table 1 . The sample of 517 farms was extrapolated to a population total of 29,816 farms across the 8 states studied.

\section{Performance Variables}

The matching methodology used in this analysis evaluated the effect of various treatments on performance outcomes. Two revenue performance outcomes were studied - milk sales ( $\$ / \mathrm{kg}$ of milk sold) and crop sales $(\$ /$ ha $)$ - to account for revenue sources on dairy

Table 1. Number of conventional dairy farms for US Department of Agriculture-Agricultural Resource Management Surveys (ARMS) sample and weighted population across states

\begin{tabular}{lcc}
\hline State & $\begin{array}{c}\text { ARMS survey } \\
\text { sample }\end{array}$ & $\begin{array}{c}\text { Predicted state } \\
\text { farm population }\end{array}$ \\
\hline California & 69 & 1,685 \\
Wisconsin & 109 & 9,207 \\
Idaho & 60 & 487 \\
Pennsylvania & 63 & 6,778 \\
Minnesota & 52 & 4,681 \\
Texas & 52 & 1,058 \\
Michigan & 56 & 1,926 \\
New York & 56 & 3,994 \\
Total & 517 & 29,816
\end{tabular}

${ }^{1}$ Predicted sample was estimated using the pweight option within STATA (StataCorp, 2011). 
farms. Purchased feed cost per kilogram of milk sold was used as the performance outcome for expenses. These outcomes allowed us to determine how revenues and expenses changed based on the various risk management treatments applied to the treatment and control groups.

\section{Risk Management Treatments}

Dairy farmers manage revenues and expenses while making production decisions to maximize profit. Often, dairy farmers use different risk management techniques to stabilize revenues and expenses. Five risk management techniques were defined as treatments for this analysis: selling milk to a cooperative, using commodity contracts to lock in a selling price for crop sales, using a nutritionist to make feeding decisions, and feeding homegrown forage at basic and intensive levels. Each treatment is explained in detail below.

Milk revenue is a function of many economic and production factors. However, when a dairy farm sells its milk plays a large role in the price received. Dairy cooperatives are common in many states and have been shown to negotiate more stable milk prices compared with other milk sale options (Mishra et al., 1993). Selling milk to a cooperative (cooperative treatment) was considered the milk revenue treatment for this analysis, coded as 1 for dairy farmers selling to a milk cooperative, and as 0 for all else (including noncooperatives and direct sales to consumers).

Using a commodity marketing contract for crop revenue allows the farmer to lock-in a selling price for their crop, which in most cases results in a higher selling price than the cash market (MacDonald et al., 2004). We expected to find commodity contracts to be a risk management tool more commonly used by dairy producers in the Midwest where corn, soybeans, and wheat are common crops raised in conjunction with the dairy enterprise of the farm as a form of diversification (McBride and Greene, 2009). We also anticipated that selling grain commodities (commodity treatment) would interact with the amount of homegrown and purchased feed used on the farm.

One of the largest expenses for dairy farms is feed (USDA-ERS, 2007). Two options exist for feed sources: purchased and homegrown feed. As stated earlier, purchased feed is the expense performance measure for this analysis; therefore, 2 levels of homegrown forage were defined as expense treatments to capture the diversity of feeding practices in the United States. The first level of homegrown forage was defined as basic, which was a yes/no response to the following question in the ARMS phase III 2010 dairy survey: "Was any harvested homegrown feed fed to dairy cattle on this operation in 2010?" An intensive homegrown variable was generated as a $1 / 0$ variable, where 1 was equal to a response that resulted in more than $65 \%$ of all feed fed to dairy cattle sourced from harvested homegrown forage. The intensive homegrown forage variable was generated to identify those dairy farms that were not sourcing the majority of their feed externally. The $65 \%$ threshold was determined by evaluating the data within ARMS and identifying the natural break for the percent of harvested homegrown forage fed.

Dairy farmers use many tools to manage milk production, which has a direct effect on both revenues and expenses. Using a nutritionist may help improve feed efficiency while managing costs. The nutritionist treatment was identified by the following yes/no question in the ARMS phase III dairy survey: "During 2010, did this operation use a nutritionist to design mixes or purchase feed?"

\section{Matching Variables}

Within each of the 8 states, 1 variable was used for exact matching and 4 variables did not require an exact match. An exact match may not exist for all observations in the data set; however, these variables are added to the $k \times k$ matrix of variables and the corresponding components in the weight matrix (Abadie et al., 2004).

This approach allowed us to match based on location, farm characteristics, and producer characteristics, providing a more comprehensive comparison than matching on one characteristic, as has been done in previous work. An exact match was based on the dairy farm herd size within the 8 states specified earlier. Following Gillespie and Nehring (2012), dairy cows were grouped into 7 herd-size categories: (1) $<50$ cows, (2) $50 \leq$ cows $<100$, (3) $100 \leq$ cows $<200$, (4) $200 \leq$ cows $<500$, (5) $500 \leq$ cows $<1,000$, (6) $1,000 \leq$ cows $<2,000$, and $(7)$ $>2,000$ cows. This herd-size classification allowed us to capture the size distribution common to the different regions, with smaller herds typically located in the Midwest and East and larger herds representative of states in the West.

We included 3 additional variables that did not require exact matching: the principal operator's education level, years of experience in the dairy industry, and the ownership structure of the dairy farm. Education level was grouped into the following 4 categories as defined in the ARMS phase III dairy survey: (1) less than high school diploma, (2) high school, (3) some college, and (4) 4-year college degree and beyond.

Past studies have shown that experience affects the risk preferences of the principal operator (Wilson et al., 
Table 2. Adoption levels (\%) of 5 risk management tools by state

\begin{tabular}{|c|c|c|c|c|c|}
\hline State & Cooperative & $\begin{array}{c}\text { Commodity } \\
\text { contract }\end{array}$ & $\begin{array}{c}\text { Basic } \\
\text { homegrown } \\
\text { forage }^{1}\end{array}$ & $\begin{array}{l}\text { Intensive } \\
\text { homegrown } \\
\text { forage }^{2}\end{array}$ & Nutritionist \\
\hline California & 81.16 & 86.96 & 77.05 & 38.10 & 81.16 \\
\hline Wisconsin & 56.88 & 17.43 & 99.04 & 89.00 & 79.82 \\
\hline Idaho & 50.00 & 31.67 & 85.96 & 49.15 & 80.00 \\
\hline Pennsylvania & 79.37 & 95.24 & 97.92 & 83.87 & 84.13 \\
\hline Minnesota & 92.31 & 21.15 & 94.23 & 92.31 & 84.62 \\
\hline Texas & 96.15 & 96.15 & 87.23 & 34.62 & 59.62 \\
\hline Michigan & 83.93 & 83.93 & 100.00 & 78.57 & 87.50 \\
\hline New York & 85.71 & 78.57 & 96.36 & 87.50 & 76.79 \\
\hline
\end{tabular}

${ }^{1}$ Survey respondent indicated that homegrown forage was fed to dairy cattle.

${ }^{2}$ Over $65 \%$ of feed fed to dairy cattle was sourced from harvested homegrown forage.

1993; Harwood et al., 1999). The ARMS phase III dairy survey did not ask about the principal operator's years of experience, but it did ask a question regarding how long milk has been produced on the farm. This variable was used as a proxy for principal operator's experience level. The principal operator's years of experience was categorized by the following 4 groups: $(1)<10$ yr dairy in operation, (2) $10 \leq$ years $<20$, (3) $20 \leq$ years $<30$, (4) $30 \leq$ years $<50$, and (5) $\geq 50$ yr.

The type of ownership structure used on the dairy farm affects how decisions are made. Ownership structure was included as a matching variable and specified by the following 5 categories in the ARMS phase III dairy survey: (1) family or individual operation (excluding partnerships and corporations), (2) legal partnership operation (including family partnerships), (3) C-corporation, (4) S-corporation, and (5) other (including estates, trusts, cooperatives, grazing associations).

In addition to matching with education, experience, and ownership structure, we included herd size again as a nonexact match to ensure we were matching dairy farms within the same size categories. By matching on these 4 variables, we were able to capture the management capability and flexibility of the dairy farm. It was assumed that those farm operators that have similar education and experience levels would utilize risk management tools in a similar manner. Using all 4 matching variables (exact and nonexact) allowed us to match farms with similar knowledge, management structure, and size to determine if the joint effect of these factors affects decisions that influence cost structure and revenues.

\section{RESULTS AND DISCUSSION}

\section{Summary Statistics}

Adoption levels for the 5 price risk management treatments are presented in Table 2. Cooperatives were the most common revenue treatment across all states, with over $90 \%$ of all respondents in Minnesota and Texas selling their milk to a cooperative. The low response rate of selling milk to a cooperative in Wisconsin $(57 \%)$ was a surprising observation considering the large number of cooperatives in the state. Commodity contracts to sell grain were commonly used by dairy farmers in California, Pennsylvania, Texas, and Michigan. As expected, using a nutritionist and feeding homegrown forage were common practices on the majority of farms across the United States. Feeding more than $65 \%$ of all forage from homegrown sources was commonly seen in Wisconsin, Pennsylvania, Minnesota, and New York. California, Idaho, and Texas had a smaller proportion of their operations using homegrown forage at an intensive level compared with the basic level.

Summary statistics for matching variables are presented in Table 3. Herd size was used as a categorical variable for matching, but the average value was reported to demonstrate the difference in herd size across time and regions for this analysis. Farms in the Northeast and Midwest states had smaller herd sizes compared with those located in the West. In the majority of states, the highest proportion of principal operators had a high school diploma, and sole proprietorships were the most common ownership structure. The experience variable captured how long milk had been produced on the farm. Across all states, excluding Texas, the most common response was 30 to 49 yr of experience. However, Minnesota and Wisconsin had the largest total proportion of producers with less than $30 \mathrm{yr}$ of experience. This further validates the fact that there is an aging population in the dairy industry and we expect that this experience dynamic affects the decision-making process for managing revenue and expense risk as the farm is transferred to the next generation or multiple generations work collectively on the same operation. 


\section{Effects of Risk Management on Performance Outcomes}

The nnmatch command in STATA was used to analyze the effects of 5 risk management tools on dairy revenue, crop revenue, and purchased feed costs for dairy farms in 8 states (Abadie et al., 2004; StataCorp, 2011). Because more than one variable was used for matching, the closest match to any particular farm was used to provide a 1:1 match for dairy farmers using risk management tool $i$. Two treatment effects were estimated - the first was the average treatment effect ATT, which measures the effect of the treatment group using risk management tool $i$. The second treatment effect estimated was ATC, which measures the outcome effect if the control group would have used risk management tool $i$. Results are presented in Tables 4, 5, 6, and 7 .

\section{Selling Milk to a Cooperative}

Dairy farms that sold milk to a cooperative (the treatment group, ATT) had higher milk sales per kilogram in Minnesota and Michigan than those farmers that did not sell to a cooperative (Table 4). In evaluating the results for the control group (ATC), we observed that California dairy farmers would have received $\$ 0.033$ / $\mathrm{kg}$ more in milk sales if they had sold to a milk cooperative. A similar result was found for dairy farmers in Pennsylvania, Minnesota, Texas, and New York. One of the more interesting results when evaluating ATT and ATC appeared when both treatment effects were significant, which was the case for Minnesota and New York. In Minnesota, 92\% of dairy farmers who sold their milk to a cooperative received $\$ 0.0384 / \mathrm{kg}$ more in milk sales than the controls. Conversely, the $8 \%$ of farms in the control group in Minnesota were matched to respondents already selling their milk to a cooperative, showing that if the control group were to have sold their milk to a cooperative, they would have increased their milk sales by $\$ 0.0670 / \mathrm{kg}$ of milk. New York had opposite results, where farmers that used the treatment received a lower milk price than the controls. This could be explained by the lower matching percentage for this treatment in New York (84\%). Conversely, if the control group in New York (14.29\% of farms) had sold to a cooperative, they would have received $\$ 0.0142 / \mathrm{kg}$ more in milk sales. Overall, selling milk to a cooperative increased milk sales per kilogram, as expected, with New York as the outlier in 2010.

\section{Commodity Contracts}

The second source of revenue on a dairy farm is crop sales. The effect of using commodity contracts as a way

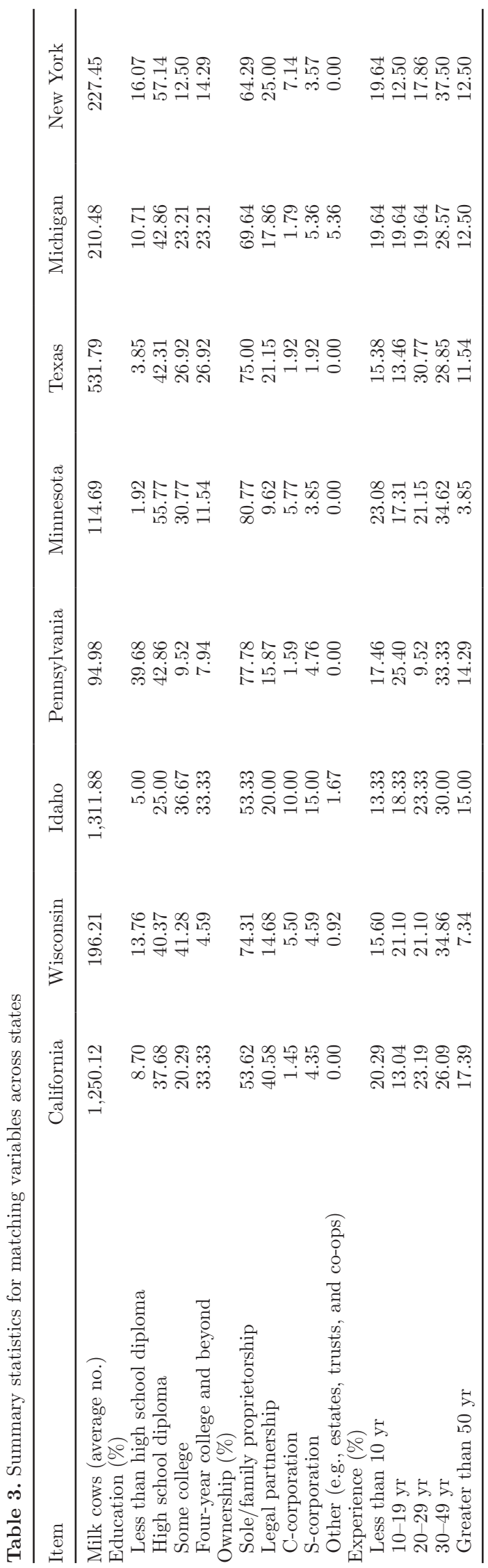

Journal of Dairy Science Vol. 98 No. 9, 2015 
Table 4. Effect of US dairy farms selling milk to a cooperative on milk price $\left(\$ / \mathrm{kg}\right.$ of milk sold) by state ${ }^{1}$

\begin{tabular}{lcc}
\hline State & $\begin{array}{c}\text { Sold to } \\
\text { co-op (ATT) }\end{array}$ & $\begin{array}{c}\text { Did not sell to } \\
\text { co-op (ATC) }\end{array}$ \\
\hline California & -0.0013 & $0.0330^{*}$ \\
Wisconsin & -0.0091 & 0.0019 \\
Idaho & -0.0025 & -0.0107 \\
Pennsylvania & 0.0140 & $0.0546^{* *}$ \\
Minnesota & $0.0384^{* * *}$ & $0.0670^{* * *}$ \\
Texas & $\mathrm{NA}^{2}$ & $0.0359^{* *}$ \\
Michigan & $0.1120^{* * *}$ & -0.0109 \\
New York & $-0.0254^{* * *}$ & $0.0142^{*}$ \\
\hline
\end{tabular}

${ }^{1} \mathrm{ATT}=$ average treatment effect using management tool; ATC $=$ average treatment effect for control.

${ }^{2}$ Denotes a state where over $95 \%$ of the respondents used that treatment.

$*, * *, * * *$ Statistically significant difference at the $10 \%(*), 5 \%(* *)$, and $1 \%(* * *)$ levels.

to lock in a selling price on crop sales is presented in Table 5. Using a commodity contract for the treatment group increased per hectare crop sales in California, Wisconsin, Idaho, Pennsylvania, and Michigan. Furthermore, for most states in the control group, using a commodity contract would have increased crop sales for $82.57 \%$ of farms in Wisconsin ( $\$ 173.47 /$ ha), $68.33 \%$ of farms in Idaho (\$63.28/ha), $4.76 \%$ of farms in Pennsylvania $(\$ 85.44 / \mathrm{ha})$, and $78.85 \%$ of farms in Minnesota (\$125.09/ha). The exception was California. If the California control group had used a commodity contract, they would have received $\$ 91 /$ ha less than originally received. This result illustrates the variation of regional effects, especially in the commodity cash market. Second, it shows the effect of using this risk management strategy in a state where the majority of feed is purchased for a dairy, as is the case for California.

\section{Using a Nutritionist}

Using a nutritionist is a common practice on most dairy farms in the United States. We anticipated that using a nutritionist would change purchased feed costs because they determine the ration mix and, in some cases, purchase the feed, and sometimes include the nutritionist fees within the feed costs. However, jointly this should increase milk production and subsequently milk sales. Texas was the only state where feed costs decreased if the treatment group used a nutritionist (Table 6). Purchased feed costs increased if the control groups used a nutritionist in California, Pennsylvania, Minnesota, and Michigan. In these 4 states, over $80 \%$ of the respondents indicated that they used a nutritionist. This demonstrates that when the remaining $20 \%$ were matched to a treated respondent, their feed costs would increase based on the treatment group's
Table 5. Effect of using a commodity contract on US dairy farm crop sales $\left(\$ /\right.$ ha) by state ${ }^{1}$

\begin{tabular}{lcc}
\hline State & $\begin{array}{c}\text { Used commodity } \\
\text { contracts } \\
(\text { ATT })\end{array}$ & $\begin{array}{c}\text { Did not use } \\
\text { commodity contracts } \\
\text { (ATC) }\end{array}$ \\
\hline California & $45.9653^{* * *}$ & $-91.3252^{* * *}$ \\
Wisconsin & $153.1742^{* * *}$ & $173.4702^{* * *}$ \\
Idaho & $51.4597^{* *}$ & $63.2815^{* *}$ \\
Pennsylvania & $107.9379^{* * * 2}$ & $85.4414^{*}$ \\
Minnesota & 25.3844 & $125.0865^{* *}$ \\
Texas & $-174.0835^{2}$ & -115.1192 \\
Michigan & $118.5036^{* * *}$ & 44.9816 \\
New York & 4.7239 & -1.4625 \\
\hline
\end{tabular}

$\overline{{ }^{1} \mathrm{ATT}}=$ average treatment effect using management tool; ATC $=$ average treatment effect for control.

${ }^{2}$ Estimate had $<75 \%$ exact matches.

$*, * *, * * *$ Statistically significant difference at the $10 \%(*), 5 \%(* *)$, and $1 \%(* * *)$ levels.

cost structure. Overall, using a nutritionist increased the cost of purchased feed. This finding complements results from Tauer and Mishra (2006), in that the use of a nutritionist does not decrease frontier unit cost but rather increases efficiency.

\section{Homegrown Forage}

Raising homegrown forage is an option for defraying purchased feed costs. Feeding homegrown forage, regardless of whether the dairy farm was in the treatment or control group, decreased purchased feed costs (Table 7). The same result held for intensive homegrown forage. However, feeding intensive homegrown forage was not significant for the treatment groups in Wisconsin, Pennsylvania, or Texas. In addition, the basic level homegrown forage treatment was not estimated for these 3 states because approximately $100 \%$ of the operations reported feeding homegrown forage

Table 6. Effect of using a nutritionist on US dairy farm cost of purchased feed $\left(\$ / \mathrm{kg}\right.$ of milk sold) by state $^{1}$

\begin{tabular}{lcc}
\hline State & $\begin{array}{c}\text { Used a } \\
\text { ntritionist } \\
(\text { ATT })\end{array}$ & $\begin{array}{c}\text { Did not use a } \\
\text { nutritionist } \\
\text { (ATC) }\end{array}$ \\
\hline California & $0.0454^{* *}$ & $0.0381^{*}$ \\
Wisconsin & $0.0200^{* *}$ & 0.0132 \\
Idaho & $0.0845^{* * * 2}$ & $-0.0760^{*}$ \\
Pennsylvania & $0.0361^{*}$ & $0.0404^{* *}$ \\
Minnesota & $0.0526^{* * *}$ & $0.0629^{* * *}$ \\
Texas & $-0.0494^{* 2}$ & 0.0017 \\
Michigan & $0.0633^{* * * 2}$ & $0.0253^{*}$ \\
New York & $0.0015^{2}$ & -0.0007 \\
\hline
\end{tabular}

${ }^{1} \mathrm{ATT}=$ average treatment effect using management tool; $\mathrm{ATC}=$ average treatment effect for control.

${ }^{2}$ Estimate had $<75 \%$ exact matches.

$*, * *, * * *$ Statistically significant difference at the $10 \%(*), 5 \%(* *)$, and $1 \%(* * *)$ levels. 
compared with the percentage of respondents that were not. Nearly all producers in these states are adopting this risk management tool, which suggests there is not much to be gained by the treatment group increasing the amount of homegrown forage fed. However, producers in the 3 states that were not feeding homegrown forage could realize significant feed cost savings if they adopted this strategy. Because California, Idaho, and Texas had fewer intensive homegrown forage adopters compared with the number of farms feeding at the basic homegrown level, it is possible that the operations using homegrown forage are limited to producing a certain amount, possibly because of competing landuse priorities. These operations have fewer opportunities to realize the feed cost savings. Although not all dairy operations have land that can produce feed, these results suggest that homegrown forage could be a costreduction strategy for those that can grow feed.

\section{CONCLUSIONS}

This research used matching methodology to estimate how decisions made by dairy farmers affect revenue and expense outcomes. This process identified each farm that was using a risk management tool and compared the performance of another farm that had similar characteristics but did not use the tool. The results of this analysis highlight the fact that a risk management technique that is beneficial in one state may not be appropriate for another state. This analysis allowed us to identify the adoption level of various risk management techniques across the United States. Overall, dairy farmers are making risk management decisions that are beneficial to their locations rather than using general recommendations. Specifically, using commodity contracts to sell grain commodities indicated a statisti- cally significant benefit to dairy farmers in the Midwest and in eastern states (Minnesota, Pennsylvania, and Wisconsin), but was not found to be a statistically significant risk management tool in western states, such as California. Western dairies are less likely to grow crops than those in the Midwest and East, whereas using commodity contracts was found to be beneficial in Idaho. Finally, feeding homegrown forages demonstrated financial benefits to the dairy. A larger effect was found in states that traditionally have smaller herds (Michigan and Minnesota) and feed their own forage compared with states that traditionally purchase most of their feed. Using the information presented in this analysis allows dairy farmers to choose a customized mix of risk management strategies that work well in their state. First, dairy farmers in California may benefit from selling milk to a cooperative and selling crops on the cash market when available. In contrast, dairy farms in Wisconsin may derive benefit from the use of commodity contracts for their crops and know that using a nutritionist may increase their purchased feed costs but at a relatively small amount compared with other states. This analysis and examples highlight the importance of educational programs targeting specific risk management tools at a regional level.

\section{ACKNOWLEDGMENTS}

The authors thank the three anonymous reviewers, as well as Amy Hagerman, Jason Lombard, Ann Seitzinger, and Bruce Wagner (USDA, Animal and Plant Health Inspection Service, Veterinary Services, Fort Collins, CO) for reviewing earlier versions of this paper and Jeff Gillespie (Louisiana State University, Baton Rouge) for guidance in using the matching methodology.

Table 7. Effect of homegrown feed strategies ( $\$ / \mathrm{kg}$ of milk sold) on US dairy farms by state ${ }^{1}$

\begin{tabular}{lccccc}
\hline & \multicolumn{2}{c}{ Basic homegrown forage } & & \multicolumn{2}{c}{ Intensive homegrown forage } \\
\cline { 2 - 3 } \cline { 5 - 6 } State & ATT & ATC & & ATT & ATC \\
\hline California & $-0.0489^{* * *}$ & $-0.0287^{*}$ & & $-0.0429^{* * *}$ & 0.0144 \\
Wisconsin & $\mathrm{NA}^{2}$ & $\mathrm{NA}$ & & -0.0027 & $-0.0630^{* * *}$ \\
Idaho & $-0.0939^{* * * 3}$ & $-0.1313^{* * *}$ & & $-0.1009^{* * *}$ & $-0.0674^{* * *}$ \\
Pennsylvania & $\mathrm{NA}$ & $\mathrm{NA}$ & & -0.0034 & $-0.0399^{*}$ \\
Minnesota & $-0.1286^{* * * 3}$ & $-0.0859^{* * *}$ & & $-0.1192^{* * * 3}$ & $-0.0864^{* * *}$ \\
Texas & $-0.1562^{* * *}$ & $-0.1355^{* * *}$ & & -0.0390 & $-0.0655^{* * *}$ \\
Michigan & $\mathrm{NA}$ & $\mathrm{NA}$ & & $-0.0258^{* *}$ & $-0.0706^{* * *}$ \\
New York & $-0.0444^{* * * 3}$ & -0.0349 & & $-0.0366^{* * *}$ & $-0.0534^{* * *}$ \\
\hline
\end{tabular}

${ }^{1} \mathrm{ATT}=$ average treatment effect using management tool; ATC $=$ average treatment effect for control.

${ }^{2}$ NA denotes a state where $>95 \%$ of the respondents used that treatment.

${ }^{3}$ Estimate had $<75 \%$ exact matches.

$*, * *, * * *$ Statistically significant difference at the $10 \%(*), 5 \%(* *)$, and $1 \%(* * *)$ levels. 


\section{REFERENCES}

Abadie, A., D. Drukker, J. L. Herr, and G. W. Imbens. 2004. Implementing matching estimators for average treatment effects in Stata. Stata J. 4:290-311.

Chang, H. H., and A. K. Mishra. 2011. Does the Milk Income Loss Contract program improve the technical efficiency of US dairy farms? J. Dairy Sci. 94:2945-2951.

D'Antoni, J., and A. K. Mishra. 2012. Determinants of dairy farmers' participation of Milk Income Loss Contract program. J. Dairy Sci. 95:476-483.

Gillespie, J., and R. Nehring. 2012. Comparing economic performance of organic and conventional US beef farms using matching samples. Aust. J. Agric. Res. Econ. 57:178-192. http://dx.doi. org/10.1111/j.1467-8489.2012.00610.x.

Harwood, J., R. Heifner, K. Coble, J. Perry, and A. Agapi Somwaru. 1999. Managing risk in farming: concepts, research, and analysis. Agricultural Economics Report No. 774. USDA Economic Research Service (ERS), Washington, DC.

Imbens, G. 2004. Nonparametric estimation of average treatment effects under exogeneity: A review. Rev. Econ. Stat. 86:4-29.

Khanal, A. R., J. Gillespie, and J. MacDonald. 2010. Adoption of technology, management practices, and production systems in US milk production. J. Dairy Sci. 93:6012-6022.

Kuethe, T. H., and M. Morehart. 2012. The profit impacts of risk management tool adoption. Agr. Financ. Rev. 72:104-116.

MacDonald, J., J. Perry, M. Ahearn, D. Banker, W. Chambers, C. Dimitri, N. Key, K. Nelson, and L. Southard. 2004. Contracts, markets, and prices: Organizing production and use of agricultural commodities. USDA-Agricultural Economic Report Number 837. http://ers.usda.gov/media/540990/aer837fm_1_.pdf.

Mayen, C. D., J. V. Balagtas, and C. E. Alexander. 2012. Technology adoption and technical efficiency: organic and conventional dairy farms in the United States. Am. J. Agric. Econ. 92:181-195.

McBride, W. D., and C. Greene. 2009. Characteristics, Costs, and Issues for Organic Dairy Farming. Economic Research Report No. 82. November 2009. USDA, Economic Research Service, Washington, DC.

McDonald, J. M., W. D. McBride, E. O'Donoghue, R. F. Nehring, C. Sandretto, and R. Mosheim. 2007. Profits, costs, and the changing structure of the dairy industry. USDA-ERS Economic Research Report No. 47. USDA Economic Research Service (ERS), Washington, DC.

Meuwissen, M. P. M., R. B. M. Huirne, and J. B. Hardaker. 2001. Risk and risk management: An empirical analysis of Dutch livestock farmers. Livest. Prod. Sci. 69:43-53.

Mishra, S. K., D. H. Carley, and S. M. Fletcher. 1993. Dairy farmers' evaluation of dairy cooperatives. Agribusiness 9:351-361.

Patrick, G. F., and W. N. Musser. 1997. Sources of and responses to risk: Factor analyses of large-scale U.S. cornbelt farmers. Pages 45-53 in Risk Management Strategies in Agriculture. R. B. M. Huirne, J. B. Hardaker, A. A. Dijkhuizen, ed. Wageningen Agricultural University, Wageningen, the Netherlands.

StataCorp. 2011. Stata Statistical Software: Release 12. StataCorp LP, College Station, TX

Tauer, L., and A. K. Mishra. 2006. Dairy farm cost efficiency. J. Dairy Sci. 89:4937-4943

Tauer, L. W. 2009. Estimation of treatment effects of recombinant bovine somatotropin using matching samples. Rev. Agric. Econ. 31:411-423.

USDA-ERS (Economic Research Service). 2005. Data-set: Milk cost of production estimates 2005-Base. http://www.ers.usda.gov/dataproducts/milk-cost-of-production-estimates.aspx\#.UnAO6hAd$\mathrm{ZQ}$

USDA-ERS (Economic Research Service). 2007. Profits, costs, and the changing structure of dairy farming. ERR-47. September 2007.

USDA-ERS (Economic Research Service). 2010. Data-set: milk cost of production estimates 2010-Base. http://www.ers.usda.gov/dataproducts/milk-cost-of-production-estimates.aspx\#.UnAO6hAdZQ

Uematsu, H., and A. K. Mishra. 2012. Organic farmers or conventional farmers: Where's the money? Ecol. Econ. 78:55-62.

Wilson, P. N., R. D. Dahlgran, and N. C. Conklin. 1993. Perceptions as reality on large-scale dairy farms. Rev. Agric. Econ. 15:89-101.

Wolf, C. A., and N. J. Olynk Widmar. 2014. Adoption of milk and feed forward pricing methods by dairy farmers. J. Agric. Appl. Econ. 46:527-541. 